\title{
Negotiating work identity
}

\author{
Authors: \\ Tamsen Saayman ${ }^{1}$ \\ Anne Crafford ${ }^{1}$ \\ Affiliations: \\ ${ }^{1}$ Department of Industrial \\ Psychology and People \\ Management, University of \\ Johannesburg, South Africa \\ Correspondence to: \\ Anne Crafford \\ Email: \\ annecrafford@telkomsa.net \\ Postal address: \\ PO Box 524, Auckland Park \\ 2006, South Africa \\ Dates: \\ Received: 07 Feb. 2011 \\ Accepted: 11 Aug. 2011 \\ Published: 10 Nov. 2011 \\ How to cite this article: \\ Saayman, T., \& Crafford, A. \\ (2011). Negotiating work \\ identity. SA Journal of \\ Industrial Psychology/SA \\ Tydskrif vir Bedryfsielkunde, \\ 37(1), Art. \#963, \\ 12 pages. http://dx.doi. \\ org/10.4102/sajip.v37i1.963 \\ Note: \\ The research this article \\ reports is the product of \\ a collaborative project \\ between the University of \\ Johannesburg and the Vrije \\ University, Amsterdam. The \\ authors acknowledge the \\ financial support from the \\ South African Netherlands \\ Research Programme on \\ Alternatives in Development \\ (SANPAD) for conducting this \\ research. The conclusions the \\ article draws or the opinions \\ it expresses are those of \\ the authors and do not \\ necessarily reflect the views \\ of SANPAD.
}

(C) 2011. The Authors. Licensee: AOSIS OpenJournals. This work is licensed under the Creative Commons Attribution License.
Orientation: The study explored the dynamics of work identity negotiation and construction.

Research purpose: The aim of the study was to investigate identity tensions and demands that mobilise identity work in the work environment.

Motivation for the study: The study hoped to improve the understanding of the dynamics of identity construction and negotiation.

Research design, approach and method: Using grounded theory methodology in the context of qualitative field research, the researchers conducted two unstructured interviews with 28 employees of a South African manufacturing company.

Main findings: The five primary dimensions the data yielded were personal identity, individual agency, social identity, social practice and job.

Practical/managerial implications: This study has implications for organisations that want to improve productivity through understanding work identity.

Contribution/value-add: The article presents a conceptual model of the demands and tensions that influence work identity.

\section{Introduction}

Work is a fundamental part of adult existence. It is a thread that runs throughout one's life, weaving a unique sense of self that becomes one's identity (Gini, 1998). It is an anchor of adulthood (Schwartz, 1982) and gives one a way to achieve success, status, power, financial security, learning, mental stimulation, self-fulfilment and to acquire knowledge (Gini \& Sullivan, 1987; Stanford, 1989). It is primarily through work that adults discover their identities and build their characters as they internalise their work experiences (Gini, 1998). Therefore, it should not be surprising that a social identity, called a work-based identity, exists.

Work identity is not a new concept. A review of the current literature shows that it is dynamic, particularly in the context of contemporary organisations (Buche, 2006; Dutton, Roberts \& Bednar, 2010; Ibarra, 2003; Kirpal, 2004). Sveningsson and Alvesson (2003) believe that work identity is important for meaning; commitment; loyalty; the logics of action and making decisions; stability and leading change; group and inter-group relations; and organisational collaboration. Wallace (2002, p. 2) defines work identity as a 'person's sense of who he or she is, constituted through his or her positioning within the particular relations of power in the workplace'. Ibarra (2003) highlights three aspects that characterise work identity. These are work activities, working relationships, the personal side of work identity and the formative events that influence who we become. According to Buche (2006), workers should identify with their tasks, responsibilities, co-workers and employers. Therefore, work identity synthesises various identities, including the person's organisational, professional and social identities.

Our turbulent and multifaceted world increasingly destabilises and threatens identity. This may lead to feelings of dissonance and incoherence. In negotiating work identity, people have to reconcile, and navigate between, the sometimes-conflicting demands and tensions that construct and position their work identity (Kreiner, Hollensbe \& Sheep, 2006; Sveningsson \& Alvesson, 2003). Given the importance of identity in various social areas, it is vital that one understands its dynamics more clearly (Albert, Ashforth \& Dutton, 2000).

Therefore, the focus of this study is to investigate the tensions and demands that allow people to negotiate their work identities. 


\section{Negotiating identity}

Throughout their lives, people are in a process of becoming as well as negotiating identity constructions amidst various roles with their associated identities and relationships (Ashforth, 2001; Beech, 2008; Ibarra, 2003; Kirpal, 2004; Sluss \& Ashforth, 2007; Snow \& Anderson, 1987; Sveningsson \& Alvesson, 2003; Swann, Johnson \& Bosson, 2009).

We call this process identity work. It aims to create a sense of coherence and distinctiveness in response to changing environments and enables one to answer the question, 'Who am I at work?' (Ibarra, 2003; Kirpal, 2004; Snow \& Anderson, 1987; Sveningsson \& Alvesson, 2003; Swann et al., 2009). Negotiating identity most often involves resolving tensions between personal and social identities (and their associated responsibilities and limitations).

Giddens (1991) calls this the struggle between individual agency and social practice as people aim to shape their environments. Social practices, in turn, try to shape them. Kreiner et al. (2006) call this a dynamic tension between uniqueness and belonging. Identification in the workplace promotes a sense of oneness or belonging to a social category or role that gives one a feeling of comfort, group acceptance and membership. It seems to increase self-esteem and improve work identity (Buche, 2006).

However, at the same time, people try to separate themselves from others by continuously defining the self in relation to others. In the face of several and often conflicting identity demands, people battle to maintain their uniqueness whilst they shift between various identity positions that specific work contexts demand (Kreiner et al., 2006). Therefore, people are central to the process of identity work.

The researchers will begin a discussion of the tension between individual and situational demands by considering the individual context or personal identity.

\section{The person at work}

Research by Rentsch and Heffner (1994) found that eight distinct components emerged in response to the question, 'Who am I?'. Kirpal (2004) calls these components of the self-concept the individual-psychological dimension. The variables in this dimension interact with the structural elements that make up the work domain. Table 1 describes these eight components.
Kirpal (2004) asserts that the person's employment history assimilates and structures these components in particular ways by incorporating personal interests, career plans, personal commitments and individual contexts. The person's work attitude moderates all of these interactions (Kirpal, 2004). All people would subjectively assess the extent to which their jobs:

- allow for personal development, learning, meaningful and challenging work, a sense of belonging and interpersonal relationships in the work domain

- contribute to their work identities (Gini, 1998; Hoogervorst, Van der Flier \& Koopman, 2004; Kirpal, 2004; Lee \& Mitchell, 1994; Sveningsson \& Alvesson, 2003).

We define our personal identities according to what we do and how we accomplish tasks. Therefore, our daily work is inherently attached to our self-concepts (Buche, 2006). Mead (1934) argued that the self arises from social processes (a 'parliament of selves') that reside within each person and that the various social contexts govern. These 'selves' may compete for power and create a dynamic tension between them.

\section{Situational identity demands regulating work identity}

Several factors act on work identity and alter the balance of these tensions. The current literature (Hoogervorst et al., 2004; Kirpal, 2004; Kreiner et al., 2006; Lee \& Mitchell, 1994; Sveningsson \& Alvesson, 2003) shows that one can discuss these factors under the headings of culture, structure, job (or role) as well as management and leadership. The individual context modifies the response to these variables and results in work identity.

\section{Culture}

Shared values and meaning amongst organisational members (Hoogervorst et al., 2004; Schein, 1985) are key constructs for understanding performance, motivation and organisational identification, the latter being an important regulator of work identity. Hoogervorst et al. (2004) add that culture helps to reduce uncertainty and keeps people in touch with the fruits of their labours by providing social integration and value patterns that serve to guide behaviour as well as to bring personal activities and organisational goals and purpose closer together.

Jackall (1988) argues that an organisation expects its members to become functionaries of the system and ambassadors of

TABLE 1: Eight components of the self-concept.

\begin{tabular}{|c|c|}
\hline Components & Description \\
\hline Ascribed characteristics & These include characteristics like gender, age, ethnicity, race, name and resources that are part of one's roots and influence one's social identity. \\
\hline Internalised beliefs & These include moral stances, values, individual preferences, religious convictions and political orientations. \\
\hline Social differentiation & This includes socioeconomic status, sexual orientation, nationality and professional affiliation. \\
\hline Self awareness & This includes individual understanding and beliefs about the self, like the idea that 'I am a good person'. \\
\hline Self determination & This includes one's beliefs about belonging, as well as self-efficacy in terms of specific tasks and goals. \\
\hline Interpersonal attributes & This refers to the personal roles that people have (like job titles) and the social characteristics that influence their individual boundaries and behaviours. \\
\hline Interests and activities & These are aspects that people enjoy and influence their work preferences and social identities. \\
\hline Existential aspects & These include personal views of the self, like level of uniqueness and quality of physical appearance. \\
\hline
\end{tabular}


the status quo. The organisation's collective conscience aims to override the wants, needs and dreams of the individual worker that could lead to the tension between social practices and individual agencies. Jackall (1988) states further that a person's work values can only include those that the organisation sanctions because the workplace creates the agenda, establishes the values and states what it expects from its employees. Research suggests that the fit between the person and the organisation's culture is more important than the person's fit within a specific role, as theories like Holland's Typology previously suggested (Robbins, Odendaal \& Roodt, 2003).

\section{Structure}

Organisational structures provide a framework for selfrealisation and identification. The regulating mechanism that structures and systems provide is a prerequisite for organisational effectiveness.

Kirpal (2004) highlights the interplay between the structural conditions of the work context and individual dispositions that situational demands trigger. She addresses structure on three levels.

The first is the macro environment. It includes the national and cultural embedding of labour markets, work concepts and vocational education as well as training systems. The second level accounts for sectoral differences and their corresponding situational demands and norms (Kirpal, 2004). The third level deals with the immediate working environment.

These structures create complex adaptive relationships. The dynamics of one system or structure can negatively affect others in the greater system. Therefore, a lack of coherence results if there is inconsistency between various structures and systems. This lack of coherence could decrease identification and generate tension in people. Sveningsson and Alvesson (2003) believe that the status quo comforts people by containing their anxiety, which is why they cling to it. One should consider this when making changes to existing structures.

\section{Job and role}

A person's vocation and the tasks involved in the job itself are important sources of situational demands that affect work identity (Gini, 1998; Ibarra, 2003). Piecemeal tasks, the division of labour, fragmentation of work, level of specialisation and role expectations may all affect work identity and people may embrace, negotiate or reject their work roles (Hammer \& Champy, 2001; Sluss \& Ashforth, 2007; Sveningsson \& Alvesson, 2003). Sveningsson and Alvesson (2003) warn that identity malaise may develop in those who feel stuck in a role that they can perform but do not personalise. This, together with frustrating roles, mobilise identity work.

\section{Management and leadership framework}

The organisation's management and leadership framework acts on work identity (Sveningsson \& Alvesson, 2003).
Participative and people-centred management practices have a more positive influence on work identity than those inherent to the bureaucratic command and control approach to management (Hoogervorst et al., 2004). Personal enablement and empowerment are important. Kirpal (2004) believes that people can achieve these through the organisation's management practices.

Authors of the current body of knowledge on work-based identity see situational factors as important (Gini, 1998; Hoogervorst et al., 2004; Kirpal, 2004; Mischenko, 2005; Sveningsson \& Alvesson, 2003). According to the Congruence Theorem, the higher the degree of fit or congruence between various components of the behavioural and situational context, the more effective the organisation becomes as people's work identities help to support organisational goals (Hoogervorst et al., 2004).

The current study was part of a larger one that explored various aspects of work identity. Its premise is that work is fundamental to negotiating and constructing peoples' identities. Individual and work related characteristics influence work identity and these factors can influence people's productivity and organisational performance. Understanding the factors that thwart or improve one's work identity can improve our understanding of developing and maintaining work identity. The research question that the current study investigates is, 'What are the identity tensions and demands that mobilise identity work at work?'

\section{Research design \\ Research approach}

The interpretive paradigm is the basis of the philosophy behind this study. It is concerned with gaining an in-depth understanding of a phenomenon in a particular context and how people create and share meaning (Rubin \& Rubin, 1995; Terre Blanche \& Durrheim, 1999).

\section{Research strategy}

The researchers designed the study around the principles of qualitative field research (Bailey, 2007). Grounded theory provides a framework for rigorous and systematic data analysis and the inductive development of theories that are particularly suited to investigating psychological processes (Charmaz, 1995; Charmaz, 2005; Glaser \& Strauss, 1967). The researchers adopted a constructivist approach to grounded theory for this study. The approach sees knowledge as a process of co-creation and the qualitative researcher uses the self as the instrument (Charmaz, 2005).

\section{Research method}

\section{Research setting}

One of the plants of a global manufacturing organisation provided the research setting. The broad range of occupations and demographics in this organisation provided exposure to an assortment of work identities, thereby increasing the transferability of the findings. 


\section{Entrée and establishing the researchers' roles}

The study was part of larger research project on work identity that SANPAD sponsored. It comprised seven students and five supervisors. The project leader negotiated access and the terms of the research with the organisation's gatekeepers.

\section{Sampling}

The researchers regarded a sample of 28 participants as large enough to yield a manageable yet comprehensive data set. Through purposive sampling, the organisation helped to identify 28 willing participants. They represented most of the business units in this plant and included the organisational structure to an executive level. This microcosm displayed variety in age, race, gender, mother tongue, level of education, occupation, socioeconomic status and worldview.

\section{Data collection methods}

Seven fieldworkers conducted 28 unstructured interviews and used them to collect their data. They allowed the participants to give first-hand accounts of their experiences in their own words (Goulding, 1999). The interviews centred on the request, 'Tell me your story'. Its specific focus was the interviewees' passions, practices and relationships (McAdams, 1993).

The fieldworkers conducted two rounds of interviews and each fieldworker interviewed four participants. They assured the participants of confidentiality and the participants gave their consent through standardised consent forms. After the first round of interviews, the researchers held a peer debriefing session to discuss the initial findings and to prepare for the second round of interviews a week later.

Another peer debriefing followed when all fieldwork was complete. The feedback the researchers gave was that they had confirmed all themes and clarified misconceptions (McMillan \& Shumacher, 2001).

\section{Recording of data}

The interviewers were responsible for transcribing their interviews fully. Some interviewers had them professionally transcribed whilst students transcribed others (Bogdan \& Biklen, 2003). The researchers shared all the transcriptions and voice recordings so that they could use all of the interviews in their study. The larger research community convened in Amsterdam to present and discuss the preliminary findings of the study using this data set.

\section{Data analyses}

In keeping with the principles of grounded theory, analysing the data was a continuous and simultaneous process. During a line-by-line analysis of the text, the researchers extracted chunks of data and assigned a code to describe the general phenomenon that the phrase or passage captured (Spiggle, 1994).

The open coding process was reductive and, when it was complete, the researchers created a spreadsheet for each code and transferred the coded chunks of data to a table in the applicable spreadsheet. They created a dictionary of all the codes. On review, it was clear that some of the codes overlapped and the researchers consolidated them into themes. They updated the tables and dictionary accordingly.

Axial coding involved comparisons between interviews and interviewees and the researchers explored the differences and similarities in the data. This process culminated in a hierarchy of codes, from which five broad concepts emerged.

The researchers found no negative cases for the five broad concepts. After several iterations, they delineated the concepts and themes clearly. Through noting the relationships between the themes and concepts, broader patterns and trends became clear and the researchers clarified the interrelationships between the concepts (Spiggle, 1994). They tested all of these relationships against the data until they developed a theory that could link all of the parts in a simple but logical way.For the purposes of this article, the researchers called the five broad concepts, which emerged in the data analysis, dimensions.

\section{Strategies employed to ensure quality data}

Brinberg and McGrath (1985, p. 174) warn that 'validity is not a commodity to be bought with techniques'. They propose that one assesses circumstances and processes throughout the research process. Robust and scientific research requires that researchers reflect on aligning their conclusions with reality throughout the process.

Throughout the project, the research team met weekly for a status update and reflective encounter. Recognised experts on qualitative research shared their knowledge and guided the research process during these gatherings. Workshops on field notes and interviewing techniques prepared the researchers. All researchers kept the methodological and inferential field notes as well as general memorandums.

\section{Reporting}

To create meaning, the crux of the interpretive paradigm, the researchers reported this study as a confessional tale (Sparkes, 2002) to do justice to the participants and their many voices.

\section{Findings}

This study showed that identity work mobilises at the interface between the person and the various social networks that one's job requires in terms of its inherent roles and responsibilities. Individual factors, identity tensions and situational demands appear to interact in the larger organisational system and its constituent parts or subsystems. The participant's need for identity work occurred on conscious and sub-conscious levels and was both voluntary and forced.

The need did not arise in a vacuum and the system induced it. This makes an account of what mobilises identity work both complex and dynamic because the fundamentals are 
inextricably interwoven. Stories are vehicles for creating meaning and making sense as we integrate the threads and weave them into a coherent whole. It is for this reason that the researchers presented the research findings via a narrative account of the themes and patterns that emerged in the anthology of short stories that they analysed.

The researchers used the two-order approach that Van Maanen (1979) and Goia (1998) suggested to present the findings. This approach includes a discussion of first order data. It includes themes and supporting quotations from the research participants.

The researchers integrated the themes, patterns and concepts that emerged from the first-order data to build a grounded theory of the forces and factors that mobilise identity work. The second order data are in the form of a conceptual model with an application value in similar cases. Figure 1 presents this model.

\section{Broad brush strokes: Unpacking the conceptual model}

\section{Personal identity}

As each narrative unfolded, the interviewees described how they 'came to be' the people they were. However, the details of how the interviewees' identities were constructed varied. 'Personal identities' appeared in all of them. Their personal identities presented reasonably stable components seated in their personalities, personal histories, value systems, ascribed resources, biographical data and loci of control. However, their interactions with others; current levels of motivation and drive; and all the things that were most meaningful to them at that particular stage in their lives moderated their personal identities.

Their personal histories included a host of factors that informed the interviewees' values, attitudes, beliefs and decisions. Upbringing, parental influence and upbringing in a collectivist or western society had a marked effect on many interviewees' concepts of work and their personal motivation and resilience. They reprioritised what was most meaningful in their lives over time. Their social identities and situational demands, which most boldly defined them in that phase of their lives, were influences. The veterans ${ }^{1}$ said they needed to ensure financial security and to leave their footprints 'in the sands of time' before they retired. Upward mobility took a back seat.

Several participants said that the apartheid government had suppressed the capacity for any ownership by African participants during the apartheid years. Therefore, exercising the freedom to build a black-owned business was very meaningful to many of the previously disadvantaged. The Broad Based Black Economic Empowerment (BBBEE) charter supported this initiative. Many African participants were using the opportunity to learn the necessary skills in this organisation whilst their businesses were in the embryonic stage.

People are continually redefining themselves and renegotiating their personal identities by engaging in identity

1.The veterans are the older participants, close to retirement and with many years of service.

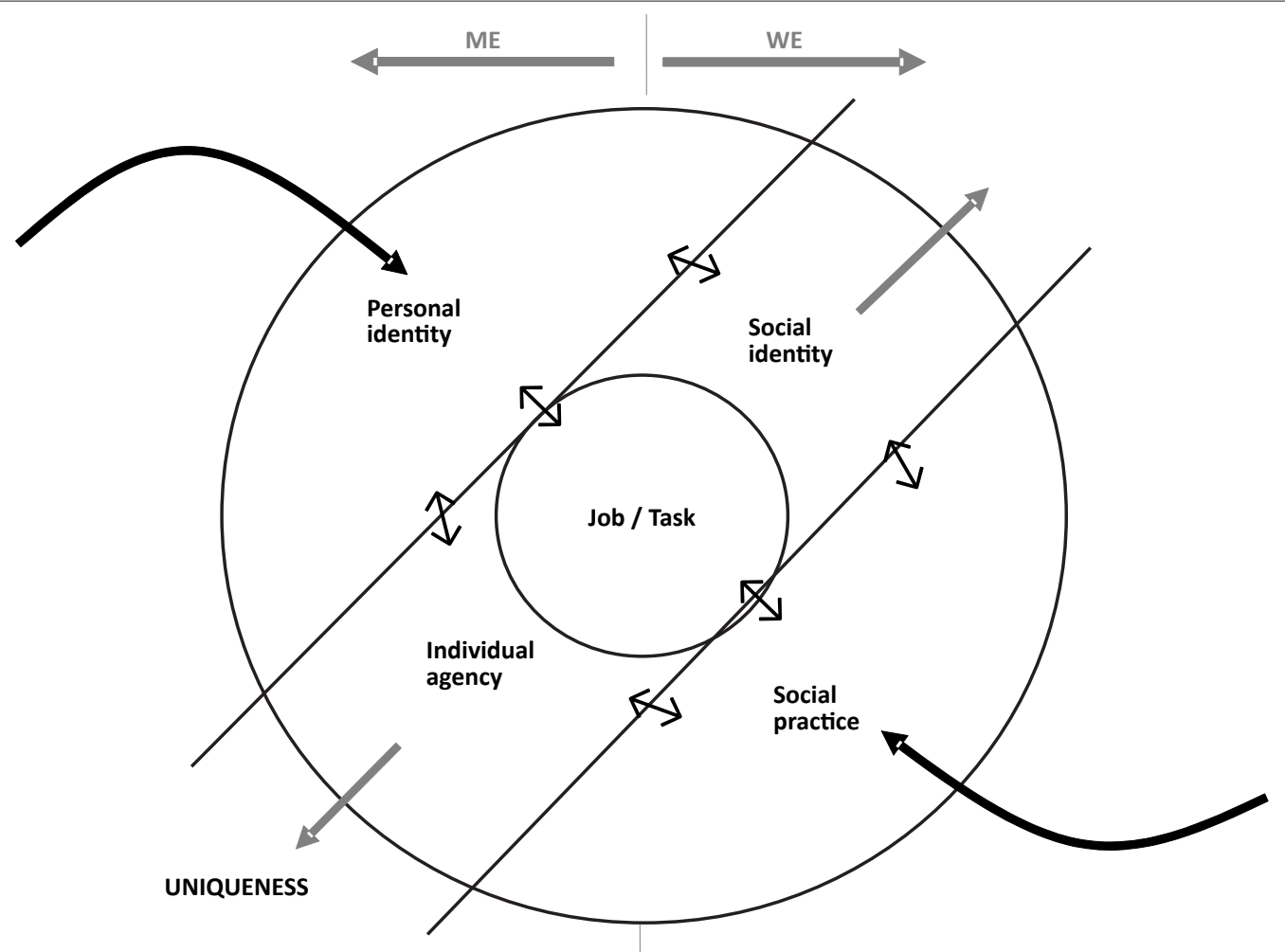

FIGURE 1: A conceptual model of the identity tensions and demands that mobilise identity work. 
work. Every time one of the participants renegotiated his personal identity to fit his meaning in the moment, he expressed an existential vacuum by making comments like, 'So after that all of a sudden now what am I gonna do? Better start my life!' and again later, 'So anyway yes, what was I going to do with my life?' [IVM1]. He needed to engage in identity work as his work-related needs had changed and he needed to realign his job with the situational demands that had changed his personal identity.

\section{Individual agency}

In the accounts of their life experiences, participants shared their defining moments, including both the low and high points, and explained how they had operationalised or expressed their personal identities to negotiate and address the situations that they now faced.

All the storytellers showed that it is through active identity expression that they define themselves as unique beings. This concept of subjective identity expression, as a means of self-determination, includes a degree of intentionality and personal control or influence. We call this 'individual agency'.

Individual agency is another key dimension in the conceptual model. Their personal identities evidently determine the extent to which people take individual agency because this moderates their need for power, affiliation and personal expression. Situational demands also play a critical role and inform people's need to exercise agency.

People's freedom to express their uniqueness appeared to have a validating and 'personalising' function as they are able acknowledge the 'me' within the larger 'we'. The opportunities, or lack of them, for individual agency in turn informed their personal identities and affected personal motivation and drive, self-esteem and their concept of work. One participant succinctly displayed his need for individual agency by stating, 'I don't like life to happen to me' [IVD2].

In exercising their personal agency, people became active role players and not passive recipients of the status quo or assigned identities. A very engaged interviewee expressed his appreciation for being allowed to exercise his individual agency in these words:

'I am in a position where I can say that we have been doing this for 20 years, let's stop doing this and try this. I have the ability. Who wouldn't appreciate that kind of environment? Work gives me the opportunity to personify that and make a difference'.

The data are rich with examples of how the respondents reacted to situations when their individual agency was at stake.

The findings showed that identity is about agency and that the self is the agent. Every interviewee presented a 'will to individual agency' and that the opportunity to exercise agency was liberating and empowering. The effect of these opportunities to take agency fostered a sense of being valued and included. Each opportunity was a micro-emancipation and its cumulative result was empowerment.

When participants could express themselves and shape their work, it also allowed them to express their uniqueness:

'I got a bit frustrated when we did the XYZ project, because the way I wanted them to do it, they didn't do it that way. And guess what guess what I'm doing now? I'm doing it like I wanted it (laughing). So it's okay and now I can do it on my own terms'.

As the system bore the participants' unique marks, it became more meaningful to them as it was effectively an expression of themselves. It was clear that this process of personal identity expression had a dual function. It allowed for personal distinctiveness and fostered feelings of having participated and thereby improved their sense of belonging.

When the organisation allowed individual agency, it strengthened relationships and social identification and the corollary was apparent. One participant, who had made a stand, said, 'They are going to try and force me to do other people's work after hours. I will not. I'll make sure my work is in order and that's that' [IVP1]. His resistance to being forced into acting against his will would negatively influence his relationships with those involved in this transaction.

\section{Social identity}

Identity is a socially constructed phenomenon that seemed to evolve in social interaction and narratives. The 'parliament of selves' that Mead refers to (in Sveningsson \& Alvesson, 2003), emerged in every story and the negotiation between sometimes conflicting situational identity demands was conspicuous. A participant explained this parliament of selves as:

'My identity is made up from my professional life, my personal life and my family life. I have got a network of friends as well. Friends that have been around for a long time...I am who I am because of my experiences... You get your true identity into the mix.'

[IVS1]

The interaction between home and work often highlighted the conflicting social identities at play, especially in those with children and in the incumbents of particularly demanding or intrusive jobs, like shift workers and stand-by staff.

Social identity was a key dimension in each participant's narrative. Examples of work-bound social identities included organisational, professional, team and role identities. However, other social identities like mother, father, husband, Black female and Christian provided further means of personal definition. Participation in communities, hobbies, studying and affiliations with other bodies also led to social identities. A participant commented, 'Systems is a completely different animal to production' [IVM1]. This illustrated the link between social identity and job role on a group level and the tensions that may arise from any interaction between these two functional groups. 
It became clear that there is a feedback loop between social identity and personal identity as social identity becomes an expression of one's personal identity and vice versa. Racial group or religious affiliation, for example, determined participants' attitudes, values and elements of their personal identity that, in turn, influenced the negotiation of social identities. The consensus was that this organisation accepts diversity well and a participant even felt that multiculturalism added a positive spin to his relationships because individual uniqueness creates interest and stimulates conversation.

Social identity was critical in influencing relationships between people in their work domains and influenced the social networks in which people operated. The dynamics of power and politics also linked to social identities, as did impression management. A technical specialist, who was fulfilled by his job, stated, 'I am now (participant's name) ${ }^{2}$, the $X_{Y} Z^{3}$ specialist' [IVD1]. His work title had become integrated with his personal identity. Another participant in a management position described himself differently, 'I am an $X$ (job title ${ }^{4}$ ) to some individuals, I am a mentor and to some individuals I'm a pain. I'm still (Name) ${ }^{5 \prime}$ [IVU2]. This interviewee was a generalist and acknowledged his many identities in his work domain. It was clear that some social identities were readily accepted and other resisted.

When identification with a role and associated social identity was weak, identity malaise decreased belonging because the participants either withdrew into themselves or expressed their differences through defiance or reduced co-operation.

\section{Social practice}

A social identity defines a framework of identity, role demands and responsibilities. It also delineates some expected behavioural norms or social practices linked to particular social systems.

Social practice appears at all levels. They include organisations, groups and the individual levels and provide implicit and explicit guidelines for operating on these different levels. On both organisational and group levels, the organisation's culture, its management and leadership practices and the structure of internal and external operating systems primarily determine accepted social practices. The structure, culture, management and leadership framework are media for organisational control. These components interact to calibrate the system and determine the rules of the game. In essence, the social practices within the organisation appeared to present the situational demands about which participants felt they needed to negotiate and to which they needed to adapt. A brief discussion of these three elements of social practice follows.

2. Name removed for confidentiality.

3.Job title removed for confidentiality.

4.Job title removed for confidentiality.

5.Name removed for confidentiality.

\section{Structure}

The macro-environment and industry sector were layers of the external structure of the system in which this organisation operates. Within the macro-environment, a number of factors seemed to influence social practices in South Africa. They include:

- personal safety

- the skills shortage

- emigration

- political and legislative issues (including apartheid)

- affirmative action

- the National Qualifications Framework

- the BBBEE charter.

Male participants mentioned that it was unpleasant working through the night knowing that their wives were scared of being home alone. Participants said that the loss of skills because of emigration delayed the filling of some vacancies, as did the need to find suitable employment equity candidates. During this time, the organisation expected interviewees to make do without necessary resources. On a sectoral level, many saw the manufacturing industry as being particularly demanding and invasive given the continuous production cycle:

'Production is harsh. We need the volume. Last night I got home at $7 \mathrm{pm}$. I reversed and was on my way back to work before I got into the house. I left work at eleven thirty. Not everyone can handle that.'

[IVQ1]

Overtime, shift work and stand-by arrangements are industry norms that influence the social practices in this industry. An interviewee explained that his working day does not end when he leaves in the evening because being contactable after hours was a job requirement. Therefore, contacting a co-worker at any hour of the night was socially acceptable in some divisions of this organisation, 'People wake me up at night - disrupt my wife's sleep and mine' [IVP1].

Issues that relate to the internal structure included the person's position in the hierarchy of the organisation and scope for upward mobility. There were also participants who felt that they lacked the positional power and authority they needed to induce delivery from co-workers because of the flat organisational structure. Subsystems, like teams or departments, have their own set of social practices. Belonging occurred on different levels and, in some cases where organisational identification was poor, strong team identification compensated and counteracted the sense of disconnection from the organisation. As people operate within the framework of a given structure, certain behaviour emerges and a unique culture develops.

\section{Culture}

The organisation's culture influenced the basic assumptions about what constitutes acceptable behaviour and contributes to the prevalent social practices in the organisation. People orientation emerged as a critical cultural element in it. Many participants mentioned the reduced people focus. One participant said, '...it sometimes tends to lose focus of the people - some people end up in file thirteen' [IVC1]. 
Longer serving participants referred to a negative culture change in the organisation. A significant number of participants said they believed that the organisation valued production numbers over people. Apparently, it drives a strong culture of numbers to the detriment of people in the organisation. One participant commented that, 'Numbers don't drive passion, they generate stress' [IVL1].

Apparently, this was not always the case in the organisation. Participants felt that the culture was depersonalising and disempowering and they no longer felt heard or included. Many expressed a loss of individual agency and exclusion from decision-making was a recurring theme:

'They used to ask input from the guys before they implemented anything. It doesn't happen anymore. It's just, listen this is what's gonna happen from tomorrow. They say people are resistant to change; people are resistant to change when it's thrust upon them'.

[IVD1]

The effect of this loss of agency seems to have filtered into the workforce's attitudes. Reduced belonging and increased withdrawal has weakened personal accountability. One participant said, 'The company values were changed without involving people - the people on the floor - and they say these are not our values' [IVD1].

Many participants mentioned accountability or personal responsibility as a cultural element, mostly with reference to more junior employees. There was a feeling that accountability was lacking and that the management practices were inefficient in correcting this. A participant commented that the organisation should strive towards, 'Giving the impression that professionalism is what's required in the work place' [IVS1].

Further explanations for the absence of accountability included:

- the increase in members of collectivist societies for which the group and not the individual is responsible

- that the organisation was becoming a training ground for young graduates

- that feelings of depersonalisation had decreased commitment to the organisation.

Without accountability, a lack of trust in co-workers emerged. This perturbed and frustrated many participants and was an issue with subordinates, team members and managers. One interviewee felt that people have an attitude of, 'Oh well it's not my job' and he then elaborates, 'So whereas before ownership was there; now there is no ownership. I'm just here for the pay. You need to pay me. There is a culture of non performance' [IVA1]. Many echoed the feeling that, 'Numbers will kick in after the softer issues have been dealt with' [IVS2] and they made a desperate call for leadership and new management practices in chorus.

\section{Management and leadership framework}

The management and leadership framework is another dimension of the model. It includes organisational leadership, relationships with managers and management practices about rewards, recognition and performance management in particular.

There was a feeling that the organisation has myopic vision and that the executive leadership team lacked a dream for the future. Operating within this team's mandate to drive production volumes aggressively and cut costs left little time for collaboration and engagement. The view was that the organisation designed its management practices to generate short-term results and forgot people in the process. Operating with a numbers culture pushed managers towards a more bureaucratic approach whilst the need for participative management practices was clear to the participants. 'Everyone must be involved, people need to be involved. Make them feel wanted, needed, as part of important part of this team' [IVD2].

There were several complaints about being micro-managed. When a manager reflected on his management approach he acknowledged that:

'...what they don't like about me is that I spend too much time with
them. I get told stay away from me now, let me do my job. I'll come
back to you'.

[IVU1]

The managers explained the rational for this as:

'You're working in a production environment that expects you to
deliver and the environment is not forgiving to you as a manager, to
you as a leader, it's not forgiving to mistakes'.

[IVU1]

The participants' experience of the social practices that emerged from the management and leadership framework was negative. One participant described it in this anecdote:

'I feel that we've got managers that are divorced because they are married to $A B C$ Organisation and they expect everybody to be the same. They can talk to you any way they want and so forth and you must just spend all your time here, like they do. I went through that. I will never do that again'.

The participant does not identify with the social practices that had previously governed and shaped his behaviour. He consciously renegotiated the boundaries within which he was prepared to co-operate with managers. In doing so, he stepped away from the collective and endorsed his right to individual agency.

Many technical interviewees, and particularly the 'old bulls', frowned upon the practice of appointing trainees as managers. They perceived the younger trainees in management positions generally as educated yet ignorant of their trade. Therefore, their subordinates disrespected and deauthorised them:

'They put people in jobs that actually can't do their job. He's just got the qualifications; he needs to learn in the job. And that guy who learns on the job is pissing people off below him. That's why I believe they start getting negative, and just resign for no reason...So yes, I think instead of having a manager in a position that's qualified they get trainees in... He's got no knowledge of the machines, he's still a little pipsqueak...he stays in somebody else's house, he can't manage money, but they put him here to handle millions'.

[IVP2]. 
The participants, who had learned their trade 'in the trenches', felt that this practice disregarded their wealth of knowledge and technical expertise.

Managers were sources of personal validation and feedback and a good relationship with team members was very important. Showing a personal interest in team members had a personalising effect that rippled into all areas of the participants' work identities. Every phone call from a manager to an interviewee who was recovering from an operation at home left a halo of excitement. A participant who likened himself to Cinderella experienced the opposite because he felt, 'Required by all and loved by none'.

These three components of social practice are interdependent. At times, tension emerged between the components of social practice because cultural norms, for example, dictated the management style the organisation used to achieve an organisational goal. It left little room for a manager to express an individual or natural style. However, management practices seemed to maintain the culture of depersonalisation that many raised. Participants believed that managers treat people as numbers in accordance with this 'numbers culture'. The structure determines spans of control that, in turn, influence the style of management.

Naturally, the social practices within the organisation and teams influenced employees in the organisation. Most of these practices shaped and moulded participants into a desired mindset or course of action. These practices act on their personal and social identities.

Employees exercise their individual agency in an attempt to influence their environment and express their distinctiveness in the group. This results in the organisation trying to shape employees using the social practices as agents whilst the employee tries to shape the social practices.

As a result, there was a dynamic tension between individual agency and social practice in every participant's story. This tension appeared in both facilitative and debilitating ways. In its optimal state, it seemed to drive innovation and progress. Employees relayed feelings of inclusion and that the organisation saw them as valued contributors. This increased their sense of belonging and improved organisational or team commitment.

Conversely, this tension harvested employees who felt that the organisation disregarded their opinions and needs continually. A professional participant noted, 'The centre is now prescriptive, so there is not much latitude' [IVK2].

As the social practices acted repeatedly on employees, this led them to feel robbed of their identities because the organisation gave them little opportunity to share their perspectives or express themselves. The organisation had suspended their individual agency and they felt that they were mere participants in their own lives. This had a depersonalising effect and led to feelings of exclusion and irrelevance. As the tension between individual agency and social practice mounted, feelings of belonging waned.

As participants shared accounts of how social practice had engulfed their individual agency, they spoke of their reduced sense of belonging. They tended to individuate and disconnect from the 'we' as they shifted focus to the 'me'. These employees illustrated their diluted organisational or team commitment and claimed that they no longer went the extra mile. This resulted in a tension between belonging and uniqueness. A sense of community seemed to be absent and it emerged as a lack of care. This was expressed as:

'In the army the circumstances were different and we depended on each other. Here no one looks after anyone else. If there was a fire, everyone would be out for themselves. In the army, you would help each other. Here we don't care about each other'.

[IVM2]

\section{Job and role}

All 28 participants were responsible for a particular set of tasks that constituted the specific jobs that they had accepted through employment contracts. The details of exactly what the interviewees call their jobs appeared in every story. Although the spectrum of activities that this involved was eclectic, the nature of the work, job demands, opportunities to learn and develop, job resources, role clarity and work as platforms for progress were distinctive themes within the job dimension.

The nature of work they performed was pivotal to each interviewee and, when referring to a previous job, an interviewee stated frankly that, 'I didn't identify with the work, I didn't enjoy it' [IBJ1]. Another interviewee with portable skills had been actively lamenting the enduring 'unhappiness in his wallet' as he patted his back pocket several times. Finally, he paused for some time before asserting that, 'I like what I do! For me to leave and do something else won't work out because I like what I'm doing!' [IVD2].

Most interviewees were particularly concerned about whether their jobs gave them meaningful work. A senior employee admitted that:

'I feel that I'm doing things on a superficial level and I'm looking at it and don't feel we are doing it well. It's a kind of emptiness. You are doing things but it's not great.

Throughout this story, it was evident that the absence of meaning in this interviewee's work had mobilised large-scale identity work at work.

The theme of job demands was a recurring grumble and participants involved in production struggled to balance their work and home lives. Most employees valued the opportunities for growth and learning in particular jobs. For one interviewee it was simply a matter of, 'When the learning stops, I move on' [IVS1]. The career opportunity that could spin off from the interviewees' current jobs was another common theme in the context of the job dimension. 
Employees' jobs are a function of the environment and they do not perform them in a vacuum. It interacts with the incumbents' personal and social identities. Furthermore, they carry them out within the ambit of the social practices that govern the organisation and teams within which the employees function. As interviewees unpacked the elements of their jobs that captivated or bored them, it was evident that the old adage of 'to each his own' applied. The very same tasks and challenges that excited and strengthened some depleted and dampened the spirits of others because people are essentially different.

Each story in this collection is a tribute to the uniqueness that lies within every interviewee. As the participants unpacked their stories, they illustrated to what extent their work domain resonated with this uniqueness and met their personal needs.

\section{Discussion}

The researchers broadened the domain of identity work into three main areas:

1. identity tensions

2. identity demands

3. the individual dimension.

One often finds the direction one needs to move forward by looking backwards. An enquiry into the current body of knowledge on work identity was the prelude to this study. All of the literature the researchers reviewed came from qualitative research findings.

There were references to what mobilises identity work. However, at the time of the literature review, the researchers found no research that focused exclusively on this aspect of work identity. This made this study the first known investigation that explicated this as the only research objective.

The work most similar to this study was that of Kreiner, Hollensbe and Sheep (2006). They investigated how people engage in identity work to negotiate the balance between their social and personal identities. In constructing this model, the work of Giddens (1991) resonated with two of the dimensions. Therefore, the researchers borrowed two of his terms when they called the dimensions 'individual agency' and 'social practice'.

A previously unidentified relationship between the two identity tensions the researchers discussed in the literature review emerged in this study. Individual agency moderates the tension between inclusion and uniqueness that Kreiner et al. (2006) identified. Exercising individual agency is essentially an active expression of one's personal identity or uniqueness and the latitude to do so fosters feelings of inclusion and results in a sense of belonging.

Kirpal (2004) and others focused on the interface between individual factors and situational or structural demands when negotiating identity. The conclusions this study draws expand this interface by accounting for the tension between uniqueness and belonging that emerged from the struggle between individual agency and social practice.

Individual factors clearly integrated with personal and social identity and played important roles in shaping who the participants were at work. Furthermore, social identities, like manager or mother, and the social practices that governed the system seemed to determine situational demands.

Social practices emerged as elements of the organisation's culture, structure and the management and leadership framework because this is what defined sociably acceptable behaviour and norms. They also determined how the organisation deals with transgressions. Time after time, the social practices seemed to govern the extent to which employees could express the uniqueness of their personal identities and take individual agency. When prevailing social practices inhibited the expression of individual uniqueness, belonging decreased and the employees tended to withdraw or disengage.

Work meant different things to different people. Its meaning altered as the employees personal and social identities changed. Regardless of where the participants placed work in their lives, they wanted and valued meaningful, challenging and interesting work.

Because of its dynamism and the interconnectedness of the five dimensions, the conceptual model acknowledges the fluidity of identity and the ongoing nature of identity work, as Ashforth (2001) stated.

Previous literature typically focused on isolated aspects of what prompts work identity. However, the model illustrates the interplay between extant theories. This study weaves the threads that lay scattered throughout the literature the researchers reviewed into a conceptual model. If one pulled one thread, the tension changed and set in motion other threads and altered the fabric of work identity.

\section{Implications of the study}

The findings of this study have noteworthy implications for those designing jobs and organisations, recruiting, supervising and managing change as well as organisational leaders. Whole jobs are more meaningful and allow people to see the fruits of their labours. Jobs should draw on the strengths and skills of people and allow them to do often what they do best. Identification with an organisation's culture and a job are important and organisations should assess them thoroughly during recruitment processes.

If organisations profess that their employees are their greatest asset, it should become theory in action and not meaningless rhetoric. They should use appropriate asset care strategies, including maintenance and reinvestment. Those supervising or managing people should take time to know and understand their people. 
Insight into the lives of people, in the broader sense, gives an insight into what they bring with them to work and what challenges they face. It also acknowledges them as people and not as cogs in a machine. People want recognition of, and feedback on, their performance, career management and opportunities for learning. They also want to feel valued. Participative management practices allow scope for individual agency and increase belonging. Coaching is more effective than coaxing and is the preferred management style. Work means different things to different people and managers should know what it means to the members of their teams.

Employees' work fits into who they are as people. When one makes changes in an organisation, one may be changing whom its people are. Engaging and including those affected is respectful and this practice is paramount for reducing resistance and maintaining a sense of identification and belonging.

\section{Future research and limitations}

There were limitations to this study. Conducting research within the boundaries of a profit-generating organisation meant that occasionally pragmatic considerations had to take precedence over paradigmatic ones when the researchers chose their sample and collected their data (Smaling, 1994).

Unlimited access to the participants was not feasible and the sample remained consistent throughout the research. These pragmatic considerations limited the feasibility of theoretical sampling researchers traditionally use in grounded theory (Goulding, 1999). Although the researchers never achieved the ideal of theoretical saturation, they did achieve category saturation. This reduced the effect of this limitation (Goulding, 1999).

Furthermore, each interviewer's unique style and personality permeated the process, thereby creating some variance in the interaction between interviewer and interviewees. Although this process counterbalanced the effect of personal differences and interviewer biases, researchers can only fully appreciate their effect on the outcomes of the interviews that they personally conducted.

Whilst individuals were engaged in identity work, they were preoccupied with resolving potential or real problems. Therefore, they were less engaged in their jobs. A better understanding of how work identity influences employee engagement would be useful. In addition, there was a large contingent of artisans involved in the study. It would have been beneficial to drill deeper and analyse how work identity affects the dynamics within this group.

Realistically, it is neither practical nor possible for all employees to exercise individual agency in all situations. This could lead to conflict in group situations. The researchers recommend further research into how work identity contributes to group dynamics.
The sample included people in different business units. Given the popularity of matrix organisational structures, the researchers also recommend further research on work identity in different occupations.

\section{Acknowledgement}

The research this article reports is the product of a collaborative research project between the University of Johannesburg and the Vrije University, Amsterdam. The authors acknowledge the financial support from SANPAD for conducting this research. The conclusions the article draws or the opinions it expresses are those of the authors and do not necessarily reflect the views of SANPAD.

\section{Author competing interests}

The authors declare that they have no financial or personal relationship(s) which may have inappropriately influenced them in writing this paper.

\section{References}

Albert, S., Ashforth, B.E., \& Dutton, J.E. (2000). Organisational identity and identification: Charting new waters and building new bridges. Academy of Management Review, 25(1), 14. http://dx.doi.org/10.5465/AMR.2000.2791600

Ashforth, B.E. (2001). Role transitions in organizational life: An identity-based perspective. Mahwah, NJ: Lawrence Erlbaum.

Bailey, C.A. (2007). A guide to qualitative field research. (2nd edn.). Thousand Oaks, CA: Pine.

Beech, N. (2008). On the nature of dialogic identity work. Organization, 15(1), 51-74.

Bogdan, R.C., \& Biklen, S.K. (2003). Qualitative research for education. An introduction to Theory and Methods. (4th edn.). Boston: Pearson Education.

Brinberg, D., \& McGrath, J.E. (1985). Validity and the research process. Beverly Hills, CA: Sage.

Buche, M.W. (2006). Gender and IT professional work identity. Michigan: Michigan Technological University, 1-6.

Charmaz, K. (1995). Grounded theory. In J.A. Smith, R. Harré \& L. Van Langenhove (eds.), Rethinking methods in psychology. London: Sage.

Charmaz, K. (2005). Grounded theory in the 21st century: Applications for advancing social justice studies. In N.K. Denzin \& Y.S. Lincoln (eds.), The Sage handbook of qualitative research. (3rd edn.). Thousand Oaks, CA: Sage.

Dutton, J.E., Roberts, L.M., \& Bednar, J. (2010). Pathways for positive identity construction at work: Four types of positive identity and the building of social resources. Academy of Management Review, 35(2), 265-293.

Giddens, A. (1991). Modernity and self-identity. Self and society in the late modern age. Cambridge: Polity Press.

Gini, A. (1998). Work, identity and self: how we are formed by the work we do. Journa of Business Ethics, 17(7), 707-714. http://dx.doi.org/10.1023/A:1017967009252

Gini, A., \& Sullivan, A.R. (1987). Work: The process and the Person. Journal of Business Ethics, 6(8), 649-655

Glaser, B.E., \& Strauss, A.L. (1967). The discovery of Grounded Theory: Strategies for qualitative research. New York: Aldine de Gruyter.

Goia, D.A. (1998). From individual to organisational identity. In D.A. Whetten \&P.C. Godfrey (Eds.), Identity in organizations: Building theory through conversations, (pp. 17-31). Thousand Oaks, CA: Sage.

Goulding, C. (1999). Grounded Theory: some reflections on paradigm, procedures and misconceptions. Working Paper Series. Telford: Wolverhampton Business School, Management Resource Centre.

Hammer, M., \& Champy, J. (2001). Reengineering the Corporation: A manifesto for business revolution. New York: HarperCollins.

Hoogervorst, J., Van der Flier, H., \& Koopman, P. (2004). Implicit communication in organisations: The impact of culture, structure and management practices on employee behaviour. Journal of Management Psychology, 19(3), 288-311.

Ibarra, H. (2003). Working identity: Uncoventional strategies for reinventing your career. Boston, MA: Harvard Business School Press.

Jackall, R. (1988). Moral Mazes. New York: Oxford University Press.

Kirpal, S. (2004). Researching work identities in a European context. Career Development International, 9(3), 199-221.

Kreiner, G.E., Hollensbe, E.C., \& Sheep, M.L. (2006). Where is the 'me' among the 'we'? Identity work and the search for optimal balance. Academy of Management Journal, 49(5), 1031-1057. 
Lee, T.Q., \& Mitchell, T.R. (1994). An alternative approach: The unfolding model of voluntary employee turnover. The Academy of Management Review, 19(1), 5189.

McAdams, D.P. (1993). The stories we live by: Personal myths and the making of the self. New York: William Morrow and Company.

McMillan, J.H., \& Shumacher, S. (2001). Research in education. A conceptual introduction. (5th edn.). New York: Longman.

Mead, G.H. (1934). Mind, self and society from the stand point of a social behaviorist. Retrieved n.d., from http://www.dominiopublico.gov.br/download/texto/ bu000001.pdf

Mischenko, J. (2005). Exhausting management work: conflicting identities. Journal of Health Organisation and Management, 19(3), 204-218.

Rentsch, J.R., \& Heffner, T.S. (1994). Assessing self concept: Analysis of Gordon's coding scheme using 'Who am I?' responses. Journal of Social Behaviour and Personality, 9, 283-300.

Robbins, S.P., Odendaal, A., \& Roodt, G. (2003). Organisational behaviour. Global and South African perspectives. Cape Town: Pearson Education South Africa.

Rubin, H.J., \& Rubin, I.S. (1995). Qualitative interviewing: The art of hearing data. Thousand Oaks: Sage Publications.

Schwartz, A. (1982). Meaningful Work, Ethics, 92, 634-646.

Schein, E.H. (1985). Organisational culture and leadership. San Francisco, CA: Jossey Bass.

Sluss, D.M., \& Ashforth, B.E. (2007). Relational identity and identification: Defining ourselves through work relationships. Academy of Management Review, 32(1), 9-32.
Smaling, A. (1994). The pragmatic dimension. Paradigmatic and pragmatic aspects of choosing a qualitative or quantitative method. Quality and Quantity, 28(3), 233-249.

Snow, D.A. \& Anderson, L. (1987). Identity work among the homeless: The verbal and construction and avowal of personal identities. American Journal of Sociology, 92, 1336-1371.

Sparkes, A.C. (2002). Telling tales in sport and physical activity: A qualitative journey. Champaign, IL: Human Kinetics.

Spiggle, S. (1994). Analysis and interpretation of qualitative data in consumer research. Journal of Consumer Research, 21(3), 491-503.

Stanford, W.F. (1989). An Instrument to Measure Adherence to the Protestant Ethic and Contemporary Work Values. Journal of Business Ethics, (80), 793-804.

Sveningsson, S., \& Alvesson, M. (2003). Managing managerial identities: Organizational fragmentation, discourse and identity struggle. Human Relations, 56(10), 1163-1193.

Swann, W.B., Johnson, R.E., \& Bosson, J.K. (2009). Identity negotiation at work. Research in Organizational Behaviour, 29, 81-109.

Terre Blanche, M., \& Durrheim, K. (Eds.). (1999). Research in practice. Applied methods for the social sciences. Cape Town: UCT Press.

Van Maanen, J. (1979). The fact of fiction in organisational ethnography. Administrative Science Quarterly, 24, 539-550.

Wallace, M. (2002). Managing and developing online education: Issues of change and identity. Journal of Workplace Learning, 14(5/6), 198-208. 